\title{
Recognition Memory without Awareness during Transient Global Amnesia
}

\author{
Pierre Mégevand Theodor Landis \\ Department of Neurology, Geneva University Hospitals and Medical Faculty, University of Geneva, \\ Geneva, Switzerland
}

\begin{abstract}
Dear Sir,
Transient global amnesia (TGA) is a fascinating syndrome of unknown etiology where anterograde episodic memory transiently ceases to function, together with a variable degree of retrograde episodic amnesia [1, 2]. Whereas transient retrograde amnesia must be caused by a reversible deficit in memory recall, the pathophysiology of transient anterograde amnesia appears less homogeneous. $\mathrm{Pa}$ tients examined during TGA were shown to display difficulties either in immediate recall of previously presented items, suggesting impairment in the encoding of memories, or in delayed recall together with an inability to recognize target items when presented with distractors, suggesting a deficit of memory storage [3]. However, some TGA patients show better performance in recognition memory than in spontaneous delayed recall, suggesting that some memories can be encoded and stored during TGA, but that their retrieval is impaired $[4,5]$.

Here, we report a patient examined during TGA who performed significantly above chance in a forced multiple-choice recognition task despite being unaware that he did, suggesting that TGA may include a deficit in the retrieval of stored memories to consciousness.
\end{abstract}

\section{Case Report}

A 55-year-old banker was brought to the hospital by his wife because of temporal disorientation and repetitive questioning that had started $2 \mathrm{~h}$ before. His past medical history included an episode of TGA 11 years previously. Evaluation took place $3 \mathrm{~h}$ after the beginning of the episode. The Mini-Mental State Examination was $22 / 30$, with mistakes on temporal orientation and word recall; the Frontal Assessment Battery was normal with 18/18 [6]. The remainder of the neurological examination was normal.

The patient had difficulty recalling events of his personal life from the past 20 years and could not recall current news events. Visuospatial anterograde memory, tested by hiding 3 objects from the patient's view in the examination room, was abolished. Auditory-verbal anterograde memory was tested using a 5-word list. Immediate recall was 5 both spontaneously and upon categorical cueing. After a distracting task of serial subtractions, delayed recall was nil. Neither categorical cueing nor providing the target word with two distractors induced recognition. However, upon forced choice, the patient correctly selected the target word 4 times out of 5 , even though he reported answering at random at each trial. Fifteen minutes later, he performed identically upon retesting with the same words.

Cerebral computed tomography and electroencephalography were normal. Twelve hours after the beginning of the episode, delayed recall was normalized. One month later, the patient had recovered both anterograde and retrograde memory, except for an amnesic gap covering the episode.

\section{Discussion}

Our patient, tested during TGA, selected the correct word 4 times out of 5 in a forced 3-choice recognition task even though he reported answering at random. According to the binomial distribution, the probability of performing at least as well in such a test by answering at random equals $11 / 243$ ( $p=0.0453$ ). The patient therefore performed significantly better than chance, suggesting that he had acquired some form of memory of the words which was sufficient to drive his behavior.

Could implicit memory drive this recognition without awareness? Priming and other forms of implicit memory are intact

\section{KARGER}

Fax +4161306 1234 E-Mail karger@karger.ch www.karger.com
Pierre Mégevand

Department of Neurology, Geneva University Hospitals

Rue Gabrielle-Perret-Gentil 4

CH-1211 Geneva 14 (Switzerland)

Tel. +41 2237233 11, E-Mail pierre.megevand@ @cuge.ch 
during TGA $[7,8]$. There is evidence that priming can improve performance in recognition tasks in the absence of awareness in healthy subjects [9] and in patients with amnesia due to medial temporal lobe damage [10]. However, these effects depend on strictly controlled experimental conditions. Additionally, amnesic patients with medial temporal lobe damage display intact priming, yet perform at chance level in recognition tasks similar to that used here [11].

We therefore hypothesize that our patient acquired an episodic memory of the words, but that retrieving this memory to conscious awareness was impaired. This implies that a retrieval deficit may participate in anterograde amnesia during TGA in addition to the previously described encoding and storage deficits [3]. It must be noted, however, that a retrieval deficit cannot be the only mechanism involved as it does not account for the aforementioned encoding and storage deficits, nor for the persistent amnesia for the episode observed in all patients [2].

Interestingly, using the binomial distribution to calculate performance probabilities in a study of TGA patients by Quinette et al. [12] suggests that 2 out of 7 (see table 4 in [12]) performed above chance at forced-choice recognition despite answering at random. Therefore, recognition without awareness might not be exceptional during TGA and should be investigated further.

\section{Acknowledgements}

We thank the patient for his consent to publication of this report. T.L. is supported by a grant from the Swiss National Science Foundation (320030_132967/1).

\section{Disclosure Statement}

The authors declare that they have no conflicts of interest.

\section{References}

1 Regard M, Landis T: Transient global amnesia: neuropsychological dysfunction during attack and recovery in two 'pure' cases. J Neurol Neurosurg Psychiatry 1984;47:668672.

2 Hodges JR, Warlow CP: Syndromes of transient amnesia: towards a classification. A study of 153 cases. J Neurol Neurosurg Psychiatry 1990;53:834-843.

7 Eustache F, Desgranges B, Laville P, Guillery B, Lalevée C, Schaeffer S, de la Sayette V, Iglesias S, Baron JC, Viader F: Episodic memory in transient global amnesia: encoding, storage, or retrieval deficit? J Neurol Neurosurg Psychiatry 1999;66:148-154.
4 Härting C, Markowitsch HJ: Different degrees of impairment in anterograde/retrograde memory and recall/recognition performance in a transient global amnesic case. Neurocase 1996;2:45-49.

5 Kapur N, Millar J, Abbott P, Carter M: Recovery of function processes in human amnesia: evidence from transient global amnesia. Neuropsychologia 1998;36:99-107.

6 Dubois B, Slachevsky A, Litvan I, Pillon B: The FAB: a Frontal Assessment Battery at bedside. Neurology 2000;55:1621-1626.

7 Kapur N, Abbott P, Footitt D, Millar J: Longterm perceptual priming in transient global amnesia. Brain Cogn 1996;31:63-74.

-8 Eustache F, Desgranges B, Petit-Taboué MC, de la Sayette V, Piot V, Sablé C, Marchal G, Baron JC: Transient global amnesia: implicit/explicit memory dissociation and PET assessment of brain perfusion and oxygen metabolism in the acute stage. J Neurol Neurosurg Psychiatry 1997;63:357-367.
9 Voss JL, Paller KA: An electrophysiological signature of unconscious recognition memory. Nat Neurosci 2009;12:349-355.

10 Keane MM, Orlando F, Verfaellie M: Increasing the salience of fluency cues reduces the recognition memory impairment in amnesia. Neuropsychologia 2006;44:834-839.

$\checkmark 11$ Stark CE, Squire LR: Recognition memory and familiarity judgments in severe amnesia: no evidence for a contribution of repetition priming. Behav Neurosci 2000;114:459467.

12 Quinette P, Guillery B, Desgranges B, de la Sayette V, Viader F, Eustache F: Working memory and executive functions in transient global amnesia. Brain 2003;126:1917-1934. 